\title{
The Development of a Theory of Rational Intertemporal Choice
}

\section{Germán Loewe}

Universitat de Barcelona

Departament de Matemàtica Econòmica, Financera i Actuarial gloewe@ub.edu

\begin{abstract}
The aim of this article is to describe the evolution of a very dynamic theory: the theory of intertemporal choice. I present the first economic thinking on intertemporal decision-making, and expose how it resulted in Samuelson's famous discounted utility model; then I describe how and why discounted utility became the standard approach to intertemporal choice in economics through the alleged normative and positive validity of dynamic consistency. Next, I review how the widening of experiments challenged discounted utility together with the dynamic consistency hypothesis, and turned intertemporal choice into a truly interdisciplinary field of research. Finally, I discuss the foundations of dynamic consistency and prove that it is neither normatively nor descriptively justified as a necessary axiom of rational intertemporal choice. I also show how until only recently, the dynamic consistency debate has had a blinding effect on the relative importance attributed to other fundamental anomalies in discounted utility. And this blinding effect can be regarded as a further side-effect of the excessive role given to dynamic consistency along these years. I thus conclude that dynamic consistency has been acting as an invisible straitjacket obstructing the development of intertemporal choice theory, and that it is only by undoing it that this field of research can achieve in the future a satisfactory understanding of human decision-making.
\end{abstract}

Key words: decision theory, intertemporal choice, rationality, dynamic consistency, experimental economics.

\section{Resumen. El desarrollo de una teoría de la elección racional intertemporal}

El objetivo de este artículo es describir la evolución de una teoría muy dinámica: la teoría de la elección intertemporal. Se presentan las primeras teorizaciones económicas sobre la toma de decisiones intertemporal, y se expone cómo desembocan en el famoso modelo de utilidad descontada de Samuelson; seguidamente se describe cómo y por qué la utilidad descontada se convirtió en el enfoque estándar de la elección intertemporal en la economía, gracias a la pretendida validez positiva y normativa de la consistencia dinámica. A continuación, se revisa cómo la extensión de los experimentos desafió las hipótesis de utilidad descontada y de consistencia dinámica, e hizo de la elección intertemporal un auténtico campo de investigación interdisciplinar. Finalmente, se discuten los fundamentos de la consistencia dinámica y se prueba que ésta no está justificada ni descriptiva ni normativamente como un axioma de la elección racional intertemporal. También se muestra cómo, hasta muy recientemente, el debate sobre la consistencia dinámica ha producido un efecto de «deslumbramiento» que ha impedido advertir la importancia de otras anomalías fundamentales en la utilidad descontada. Y este efecto puede ser considerado como un efecto lateral más del excesivo papel otorgado a la consistencia dinámica durante esos años. 
Se concluye, así, que la consistencia dinámica ha actuado como una camisa de fuerza invisible que ha obstruído el desarrollo de la teoría de la elección intertemporal, y que sólo erradicándola podrá este campo de investigación alcanzar en el futuro una comprensión satisfactoria de la toma de decisiones humana.

Palabras clave: teoría de la decisión, elección intertemporal, racionalidad, consistencia dinámica, economía experimental.

\section{Contents}

The Origins of Intertemporal Choice Theory

The Birth of Discounted Utility

Dynamic Consistency and the Final Establishment of Discounted Utility

Anomalies in Discounted Utility: The Experimental Challenge
Intertemporal Choice after the Experimental Challenge: Rationality as Dynamic Consistency Reconsidered Summary and Conclusions

References

On the $13^{\text {th }}$ of September 1848 a horrible accident occurred near Cavendish, Vermont. When the foreman of a railway construction gang was preparing an explosion, he started tamping directly onto the explosive powder with his iron rod. The sparks immediately struck fire, producing a big blast that shot up the iron rod towards the man's head. The iron penetrated his left cheek bone and went out through the top of his head, crossing the whole frontal part of his brain and landing 300 feet away. His name was Phineas Gage, and every student in neurology knows today the rest of the story. He survived the accident without any apparent damage to his mental capacities. He could even return to work in a few weeks, and no difference was to be observed in his behavior. But, according to everyone who had contact with him thereafter, there was in fact one difference: Phineas Gage had become impulsive, capricious and completely unable to plan ahead, and spent the rest of his life drifting in the moment, from one abandoned job to another, until his early death at age thirty-eight (Damasio 1994; Macmillan 2000).

Neurobiology knows today that a variety of activities occurring in the prefrontal cortices regulate our capacity to undertake planned behavior (Manuck, Flory, Muldoon \& Ferrell 2003). Damages of this brain area have been found to affect one's ability to control impulses and execute plans, ability that turns out to be of crucial importance to conduct a normal life. In essence, every person needs to be able to postpone rewards, and follow a plan that demands sacrifice in the present and yields benefits in the long run. Almost any decision we make includes this ability: we put effort in our job to improve our position and get recognized in the future; we save money now in order to be able to buy something later; we diet in March in order to look better in July.

But not always postponing rewards is advisable. Sometimes, we are also told how important it is to enjoy the moment and stop thinking on the future 
consequences of our actions. In the extreme, it seems quite obvious that we should not postpone all rewards systematically to the future, since in that case we would never see the benefits of our decisions materialized. Strictly speaking, the question of when to choose a smaller-sooner reward over a larger-later reward $^{1}$, and when to choose vice versa, remains unanswered. Social science has, nevertheless, studied this topic in depth, both from a normative and from a positive perspective. A theory of intertemporal choice has developed over more than two hundred years to become, today, one of the most effervescent fields of social research.

In the beginning, intertemporal choice was a purely economic theory; but along these years this discipline has turned into an interdisciplinary field of research involving psychologists, economists, sociologists, mathematicians, neuroscientists, ethologists, etc., all mutually benefiting from their respective findings ${ }^{2}$. As a result, intertemporal choice models have been scrutinized for the last twenty-five years by hundreds of experiments and alternative theories, challenging the standard formulations made by economists in the first half of the twentieth century, and significantly improving the understanding of human decision making. We know how people react in many situations; we know, for instance, that people are more impatient for small amounts of money than for big amounts; that people prefer an increasing sequence of money over a decreasing one; or that the framing of intertemporal choice problems strongly affects decisions, for example. But while much of this knowledge contradicts the standard economic theory, no clear alternative model has yet emerged. Intertemporal choice consists in our days of a collection of theoretical alternatives, each of them explaining only part of the empirical evidence.

The way intertemporal choice has developed over the last two centuries perfectly exposes the difficulties of an economic theory to achieve empirical validity. Intertemporal choice went successfully through two decisive steps: first, a clear mathematical formulation made possible that experimentalists knew what to test; second, both economists and researchers from neighbor disciplines started examining the generated evidence and collaborated in finding better models. But in its path, I will argue, intertemporal choice has had to confront a particularly strong obstructing force. What this obstacle has been and how it has been overcome, both are the object of analysis of this paper. The plan is as follows: in the next section I will describe the first economic theories of intertemporal choice; then I will present discounted utility, the theory that established as the standard in the twentieth century; next I will describe the experimental challenge to this theory appeared in the last decades; and finally, I will analyze the main obstacle found by intertemporal choice in its path to supersede discounted utility. In the conclusions I will try to extract the lessons

1. Or, put in terms of punishments, a larger-sooner punishment over a smaller-later punishment.

2. See Loewenstein, Read \& Baumeister 2002 (eds.) for a collection of recent contributions to intertemporal choice from different disciplines. 
that can be drawn from this process for the development of other economic theories.

\section{The Origins of Intertemporal Choice Theory}

The idea that the value of a good depends on the timing of its consumption was already present in the economic thought of the $18^{\text {th }}$ century ${ }^{3}$. But an in-depth study of the economic and psychological motivations underlying time preference had to wait until the publication in 1834 of The Sociological Theory of Capital, written by who is in consequence considered the father of intertemporal choice modelling: John Rae ${ }^{4}$. According to Rae, someone's time preferences are explained by his "effective desire of accumulation». And this desire, he claimed, is determined by the following four factors:

I. The Bequest Motive

II. Self-restrain

III. Uncertainty of Human Life

IV. Excitement of Immediate Consumption

Factors I and II are considered to promote the desire of accumulation, while factors III and IV are supposed to limit it. But all four factors jointly determine a person's time preference. Thus, for example, the more uncertainty an individual has over his life (factor III), the less he will care about the future, and, consequently, the lower will be his desire of accumulation. On the other hand, the higher his affections towards his heir (factor I), the more value he will give to the future, and, consequently, the higher will his desire of accumulation be $\mathrm{s}^{5}$.

The marginalist William Stanley Jevons took years later the following more technical view (Jevons 1888 [1871]): to maximize total utility (pleasure) over time, a person ought to distribute consumption of a good over ' $n$ ' days so as to equal each days' marginal utility ${ }^{6} v_{i}$ times the probability $p_{i}$ of the good remaining consumable:

$$
v_{1} p_{1}=v_{2} p_{2}=\ldots v_{n} p_{n}
$$

3. Even a formula for present value existed already in that times, thanks to contributions like that of Halley, more famous for the comet that bears his name. (Mark Rubinstein 2003).

4. The relevance of Rae's work as a pioneering one in this topic is made clear by Irwin Fisher's dedication of his famous Theory of Interest: "To The Memory of John Rae and of Eugen von Böhm-Bawerk Who Laid the Foundations Upon Which I Have Endeavoured to Build» (Fisher 1930).

5. And, hence, according to Rae, the higher his nation's wealth will be. Interestingly, Rae's own theory on the Wealth of Nations was precisely based on the different desire of accumulation of their inhabitants. (Fredrick, Loewenstein \& O’Donoghue 2002)

6. Marginal utility is the utility of the last unit of consumption. If one drinks three beers in a row, the third glass contributes probably less to our wellbeing than it does the first. Economists refer to this preference pattern by saying this person has decreasing marginal utility for beer. 
Imagine, for instance, that an individual has to decide when to drink three bottles of very good wine in the next three days. Since the probability of the wine remaining good for the next days is almost equal to one $\left(p_{1}=p_{2}=p_{3}=1\right)$, Jevons' formula would recommend that he does not drink all of it in the first day, since, in that case, and due to decreasing marginal utility - where more consumptions implies lower marginal utility-, $v_{1}$ would be lower than $v_{2}$ and $v_{3}$, and the equality would not hold. The underlying idea is that one ought to distribute consumption over time so as to maximize total pleasure, and not over-consume in one period to the expense of the others. If, instead of wine, one were to decide on the consumption of three bottles of, say, milk-shake, the same formula would suggest concentrating consumption in the present, under the risk of it becoming inconsumable later.

In general, since $\left(p_{i}\right)$ is to be assumed a decreasing sequence for obvious reasons, this equation predicts that an individual's allocation to future consumption of any commodity will be less than his allocation to present consumption, since, for future periods, a lower probability will have to be compensated with a higher marginal utility, and to obtain a higher marginal utility you need to consume a smaller amount of the commodity ${ }^{7}$. Thus, Jevons assumed that, owing to the fact that there is an intrinsic uncertainty on whether future consumption is ever going to happen, there is a rational preference for present over delayed consumption. But he also acknowledged an irrational time preference, due to men not being perfectly foresighted. To take this fact into account, he defined $q_{1}, q_{2}, \ldots, q_{\mathrm{n}}$ to be «the undetermined fractions which express the ratios of the present pleasures or pains to those future ones from whose anticipation they arise» (Jevons, 1888, III.62). Such discounting factors entered his previous equation to make it as follows:

$$
v_{1} p_{1} q_{1}=v_{1} p_{1} q_{1}=\ldots=v_{n} p_{n} q_{n}
$$

We can immediately see how these new 'irrational' factors become a further explanation of why people allocate less consumption to the future than to the present. It is natural to assume that instant pleasures will be more valued than the anticipation of the same pleasures. If, in consequence, $\left(q_{i}\right)$ is considered a decreasing sequence too, then equation (2) means that individuals allocate lower consumption to the future than to the present for two distinct motives. One is deemed rational -intrinsic uncertainty on the mere possibility of future consumption - while the other is considered irrational —undervaluation of future pleasures-.

7. That lower consumption means higher marginal utility is true only under the assumption of diminishing marginal utility of consumption. Under this view, there are then two competing forces: diminishing marginal utility invites us to postpone consumption because of satiation, while uncertainty on the good remaining consumable recommends us not to do it. Note that, without the assumption of diminishing marginal utility, there would be no reason (in this framework) not to consume all available quantity of a good in the present. 
In 1884, Eugen von Böhm-Bawerk (1890) claimed that this systematic tendency to underestimate future pleasures may be due to humans lacking the capacity to make a complete picture of their future wants, especially when it comes to remotely distant ones ${ }^{8}$. Böhm-Bawerk's voluminous work Capital and Interest was entirely devoted to the study of time preferences and it developed the methodology, already present in Jevons ${ }^{9}$, of considering the allocation to different consumption periods a technical question; in essence, a matter of efficiency.

This 'technical' approach was further perfected by the American economist Irwin Fisher, who achieved a formalization of time preference in terms of economic trade-offs among consumption in two different periods (Fisher 1930). According to Fisher, every person has his own rate of 'impatience', one that depends upon objective factors (size and risk of future income) and subjective factors (foresight, strength of will, habit, uncertainty, selfishness, influence of fashion). But Fisher's theory aimed at describing equilibrium in the financial market, where - he thought - all different rates of impatience would have been homogenized by the market interest rate (through borrowing and lending).

\section{The Birth of Discounted Utility}

As his predecessors, Fisher's great insight into time preferences already announced the basic economic relations in intertemporal choice. But neither Fisher nor Böhm-Bawerk or Jevons achieved to propose a specific mathematical function describing time preferences in general (for any number of outcomes and periods). It was the economist Paul Samuelson (Samuelson 1937) who found a solution in a very influential paper entitled «A Note on the Measurement of Utility». Building on all previous knowledge, Samuelson investigated what mathematical structure makes it possible to explain intertemporal choices for any number of periods. Finding such a structure required making several assumptions. A most fundamental one was that «the individual behaves so as to maximize the sum of all future utilities». Mathematically, the individual was supposed by Samuelson to behave so as to maximize the following function ${ }^{10}$ :

8. This line of research has been lately further developed in Loewenstein, O'Donogue \& Rabin (2003), who show that people systematically tend to mispredict their future utility by considering it too similar to their current utility. (People systematically fail to predict how quickly they will adapt to being rich after having won the lottery, for example)

9. I depart here of the opinion of Fredrick, Loewenstein \& O'Donoghue (2002) who consider Böhm-Bawerk to be the first to favour this methodology. My position is based on the formulae just presented, where Jevons clearly argues for an allocation that maximizes utility over different periods as if they were different alternative 'uses' of the good.

10. I will here reproduce Samuelson's theory in a discrete-time setting; Samuelson himself developed his argument in a continuous setting. 


$$
U^{0}=\sum_{\mathrm{t}=0}^{\mathrm{T}} \mathrm{V}(\mathrm{x}, \mathrm{t})
$$

where $V(x, t)$ is the utility value of income $x$ occurring in time distance $t$. But, according to Samuelson, future utility is not directly comparable to present utility. Future utilities need to be «reduced to comparable magnitudes by suitable time discounting», in his words. His idea, much in the spirit of Jevons and other predecessors, was to introduce the common intuition that a good in the future is less valuable than receiving the same good today. Now the natural question to ask is how should such a discounting of future magnitudes occur? And here came Samuelson's most decisive assumption: discounting was considered independent (separate) from utility. An individual's time preferences were disentangled into a regular utility function for money ${ }^{11} \mathrm{U}(\mathrm{x})$ —also called 'instantaneous utility'-, and a discount function $D(t)$ that assigns a weight to utility at every time period. The original utility function can in consequence be substituted by the following one:

$$
\mathrm{V}(\mathrm{x}, \mathrm{t})=D(t) \cdot \mathrm{U}\left(\mathrm{x}_{\mathrm{t}}\right)
$$

The individual is assumed to have an 'instantaneous utility' for the money quantities at every period, $\mathrm{U}\left(\mathrm{x}_{\mathrm{t}}\right)$. This function does not depend on the timing of consumption; it is supposed to represent the pleasure ${ }^{12}$ one derives in the moment of consumption. Any time preference is thus confined to the discount function $D(t)$. And in consequence, the individual is now assumed to maximize the following utility function:

$$
U^{0}=\sum_{t=0}^{T} D(t) \cdot \mathrm{U}\left(\mathrm{x}_{\mathrm{t}}\right)
$$

The disentanglement of value into instantaneous utility and discount function is an arbitrary assumption that imposes a particular structure on time preferences. Samuelson did, thus, impose two fundamental —and arbitraryassumptions: behaviour as maximization of the sum of future utilities, and discounting of future utilities computed as a separate function.

But in fact, Samuelson went further and proposed a specific discount function to solve his measurement problem: Samuelson assumed that people discount future amounts by means of an exponential function. The choice of exponential discounting was inspired by the following reasoning: when an

11. Samuelson's theory was intended to explain only preferences over money income. Nevertheless, his theory has been used in very different domains.

12. Modern economics does not anymore identify utility with pleasure. I have used this term to better illustrate what instantaneous utility is intended to be. A more technical interpretation of a utility function is the following: values assigned to every choice alternative make it possible for us to explain observed behaviour as if the individual aimed at maximizing those values. Only under the 'benthamite' assumption that people's behaviour is exclusively explained by their seeking of pleasure and avoiding of pain both concepts of utility share the same meaning. 
individual sacrifices consumption of money in the present in order to save it for the future, it is natural to assume that he takes into account the fact that money will yield an interest during this time (Samuelson 1937). And it was simplest for Samuelson to compute this interest as a 'constant compounded interest', the most standard way of computing interests in financial economics. Let us briefly follow his reasoning: under compounded interest, any amount $X_{0}$ yields a total interest of $i \cdot X_{0}$ during the first period, becoming $X_{1}$ in period one:

$$
X_{1}=X_{0}+\mathrm{i} \cdot X_{0}=X_{0} \cdot(1+i)
$$

For a total of $t$ periods, and under the assumption of equal (constant) interest rate for each period, we find that:

$$
\begin{aligned}
& X_{1}=X_{0} \cdot(1+i)^{1} \\
& X_{2}=X_{1} \cdot(1+i)^{1}=X_{0} \cdot(1+i)^{2} \\
& X_{3}=X_{2} \cdot(1+i)^{1}=X_{0} \cdot(1+i)^{3} \\
& \ldots \\
& X_{\mathrm{t}}=X_{\mathrm{t}-1} \cdot(1+i)^{1}=X_{0} \cdot(1+i)^{t}
\end{aligned}
$$

This model is usually referred to as 'constant compounded interest', and can be used to compute the total interest a certain amount of money will yield in a certain period. Now Samuelson used $X_{\mathrm{t}}=X_{0} \cdot(1+i)^{t}$ to define a discount function by simply inverting the terms:

$$
\begin{aligned}
& X_{t}=X_{0} \cdot(1+i)^{t} \\
& X_{0}=X_{t} \cdot \frac{1}{(1+i)^{t}} \\
& X_{0}=X_{t} \cdot D(t)
\end{aligned}
$$

or

$$
D(t)=\frac{1}{(1+i)^{t}}
$$

Now we can enter this discount function into Samuelson's previous formulation:

$$
U^{0}=\sum_{t=0}^{T} \frac{1}{(1+i)^{t}} \cdot \mathrm{U}\left(\mathrm{x}_{\mathrm{t}}\right)
$$

The result is the most widely used model for intertemporal choice: the socalled discounted utility model ${ }^{13}$. Its elegance and parsimony is undisputed,

13. Thus, when economists refer to discounted utility, they normally mean exponentially discounted utility. 
and economists all over the world adopted it almost instantly as their standard approach. Time preference was now captured into one single parameter: the discount rate $i$. And the model is intuitive enough so as to be regarded as plausible. The main relations are explained: the later an amount, the lower its present equivalent value; more impatience (higher $i$ ) means stronger discounting at every period; higher instantaneous utility of an outcome in the future means higher present value in the same proportion; and a sequence of future outcomes is valued today as the sum of each outcome's present value. At first glance, the model was no doubt a sensible tool to describe intertemporal choices.

\section{Dynamic Consistency and the Final Establishment of Discounted Utility}

While the scientific community was rapidly assimilating discounted utility, Samuelson himself had proven very skeptical about it: "The idea that such a [mathematical] investigation could have any influence upon ethical judgments of policy is one which deserves the impatience of modern economists", wrote Samuelson (Samuelson 1937). He saw his result as a pure mathematical finding, and was perfectly aware of the many assumptions underlying the theory. One of them was particularly worrying: the choice of exponential discounting. Why exactly were people to discount exponentially? As we just saw, the rationale for it given by Samuelson was based on the way interest is computed in the financial world. But, why would someone's impatience necessarily have the structure of compounded interest?

In 1956 Robert Strotz gave the answer (Strotz 1956): exponential discounting is the only discount function that guarantees the principle of dynamic consistency. In other words, Strotz showed that if an individual's time preferences had a structure different from exponential discounting, then he would be unable to follow his own plans. Suppose an individual prefers $€ 110$ in 3 days over $€ 100$ in 2 days, but prefers $€ 100$ now over $€ 110$ tomorrow. From the distance, he prefers the larger-later amount, but once he approaches consumption, he cannot stick to his previous decision and decides to go for the smaller-immediate amount. Such an individual would plan a certain action and continuously reconsider his decision without ever being able to stick to previous plans, much like Phineas Gage after his terrific accident ${ }^{14}$.

After Strotz' contribution, the choice of exponential discounting was not an arbitrary choice anymore, nor a choice of convenience; exponential discount-

14. In fact Strotz went one step further and considered the case where an individual with nonexponential preferences is aware of his own dynamic inconsistency problem. In that case, Strotz argued, we can think of two strategies in front of inconsistency: either the individual uses commitment devices, as when Ulysses tied himself to the mast; or he considers only those actions that will entail no inconsistency problem. (Strotz was the first to use the famous Ulysses and the Sirens example as early as 1956) 
ing was found to be now the rational standard in intertemporal choice, one based on the fundamental intuition that any normal person is in fact able to plan ahead. Next I present a synthetic version of Strotz' mathematical argument.

Suppose it is Friday and an individual — call him Alex - realizes this weekend he only can afford $k$ hours of his preferred activity — watching sports on TV - for he needs to get an academic presentation finished by Monday. He thus decides to allow himself a total of $k$ hours TV within the weekend, and to spend the rest of the time working on his presentation. His preferences are such that the pleasure he derives from watching TV marginally decreases with time ${ }^{15}$. Now suppose Alex's preferences at time $\tau$ over the set of all possible TV consumption paths can be represented by the following utility function:

$$
u_{\tau}\left(x_{0}, \ldots, x_{T}\right)=\sum_{t=0}^{T} D(t-\tau) \cdot \ln \left(x_{t}\right)
$$

where $\ln \left(x_{t}\right)^{16}$ is an 'instantaneous utility function' assigning a value to every amount of TV hours $x_{t}$ at time $t$, while $D(t-\tau)$ is a general discount function that weighs the utility of consumptions depending on the timedistance between a future (or past) date $t$ and the present moment $\tau$ ( $T$ being the total number of periods). In other words, suppose Alex behaves as if he maximized the discrete-time equivalence to Samuelson's previous function (2), in which we have specified the instantaneous utility function (as a logarithmic one), but left unspecified the discount function. We can now ask what maximization problem does in fact face Alex on Friday. If we use $d_{t-\tau}$ for $D(t-\tau)$, Alex's utility as seen on Friday (at $\tau=0$ ) is the following:

$$
u_{0}\left(x_{0}, x_{1}, x_{2}\right)=d_{0} \ln \left(x_{0}\right)+d_{1} \ln \left(x_{1}\right)+d_{2} \ln \left(x_{2}\right)
$$

where $x_{0}, x_{1}, x_{2}$ are, respectively, TV hours watched on Friday, Saturday and Sunday. And his optimization problem is to maximize utility over the weekend subject to the constraint of not watching more than $k$ hours TV.

$$
\begin{aligned}
& \max u\left(x_{0}, x_{1}, x_{2}\right) \\
& \text { s.t. } \\
& x_{0}+x_{1}+x_{2}=k
\end{aligned}
$$

Using Lagrange multipliers we find the following first-order conditions for a maximum:

15. The problem becomes trivial if that is not the case: under the assumption of positive time preference, in the absence of marginally decreasing utility Alex would allocate all budgeted leisure into the nearest possible period. It is the assumption of diminishing marginal utility that makes intertemporal choice problems interesting, since it constitutes a counterbalance to positive time preference.

16. Logarithmic functions are often used to describe utility of consumption because they are marginally decreasing. 


$$
\begin{aligned}
& x_{0}^{*}=\frac{d_{0}}{d_{0}+d_{1}+d_{2}} k \\
& x_{1}^{*}=\frac{d_{1}}{d_{0}+d_{1}+d_{2}} k \\
& x_{2}^{*}=\frac{d_{2}}{d_{0}+d_{1}+d_{2}} k
\end{aligned}
$$

This means Alex should distribute his consumption ( $k$ hours) over the weekend according to how he relatively values consumption occurring at different time-distances.

Now let us look at what decision-problem he faces one day after, on Saturday (before consumption). For the sake of simplicity, let us assume, $d_{-1}=d_{-2}=0$, i.e. the discounted value of past consumption is zero. Utility as seen from the point of view of Saturday (at $\tau=1$ ) is then

$$
\begin{aligned}
u_{1}\left(x_{0}, x_{1}, x_{2}\right) & =d_{-1} \ln \left(x_{0}\right)+d_{0} \ln \left(x_{1}\right)+d_{1} \ln \left(x_{2}\right) \\
& =d_{0} \ln \left(x_{1}\right)+d_{1} \ln \left(x_{2}\right)
\end{aligned}
$$

and first-order conditions for a maximum are:

$$
\begin{aligned}
& x_{1}^{* *}=\frac{d_{0}}{d_{0}+d_{1}}\left(k-x_{0}^{*}\right) \\
& x_{2}^{* *}=\frac{d_{1}}{d_{0}+d_{1}}\left(k-x_{0}^{*}\right)
\end{aligned}
$$

A natural question to ask now is under what conditions will $x_{1}^{* *}$ equal $x_{1}{ }^{*}$; in other words, when will optimal consumption for Saturday as seen from the standpoint of Friday $\left(x_{1}^{*}\right)$ equal optimal consumption for Saturday as seen from the standpoint of Saturday $\left(x_{1}^{* *}\right)$, i.e. when will Alex behave dynamically consistent in this problem. Making both expressions equal we obtain the answer:

$$
\begin{aligned}
& x_{1}^{*}=x_{1}^{* *} \\
& \frac{d_{1}}{d_{0}+d_{1}+d_{2}} k=\frac{d_{0}}{d_{0}+d_{1}}\left(k-x_{0}^{*}\right) \\
& (\ldots) \\
& \frac{d_{1}}{d_{0}}=\frac{d_{2}}{d_{1}}
\end{aligned}
$$

Hence, a necessary and sufficient condition for the consistency of Alex's behavior is that the relative importance of Saturday and Sunday is the same both from the point of view of Friday and Saturday. An inconsistency may 
thus only arise if Alex does not discount time according to this particular structure. It can be shown that this argument extends to any number of periods, implying that, in general, it is needed that

$$
\frac{d_{1}}{d_{0}}=\frac{d_{2}}{d_{1}}=\ldots=\frac{d_{n}}{d_{n-1}}=\delta
$$

which, if you assume $d_{0}=1,{ }^{17}$ means the discount function must consist of discounting the same proportion $\delta$ in every period:

$$
D(t-\tau)=\delta^{t-\tau}
$$

Since we can always express the constant discount factor as a function of a discount rate, we find that

$$
\begin{aligned}
& \delta=\frac{1}{(1+i)} \\
& D(t-\tau)=\delta^{t-\tau}=\frac{1}{(1+i)^{t-\tau}} \\
& D(t)=\delta^{t}=\frac{1}{(1+i)^{t}} \quad \text { for } \tau=0 \text { (point of view of the present) }
\end{aligned}
$$

This formulation is exactly Samuelson's proposed exponential discount function. For a positive $i$, the discount factor $\delta$ is a number smaller than 1 , thus expressing the idea that the value of an amount in the future is to be 'discounted' to find its equivalent in the present.

The result, as Strotz proved in a more general setting, is that, in order to rule out dynamic inconsistency from the individual's behavior, we need to assume exponential discounting, or, as it is often labeled, constant discounting. Constant discounting means that in every period the same discount rate (or factor) is applied, and thus the same proportion of value is discounted. Take, for example, the choice among (€110, 31 days) and (€100, 30 days). Exponential discounting implies that if someone prefers the first to the latter, then

$$
110 \cdot \delta^{31}>100 \cdot \delta^{30}
$$

But then also

$$
\begin{aligned}
& \frac{110 \cdot \delta^{31}}{\delta^{30}}>\frac{100 \cdot \delta^{30}}{\delta^{30}} \\
& 110 \cdot \delta>100
\end{aligned}
$$

17. A natural assumption to make: utility at delay zero should equal instantaneous utility. 


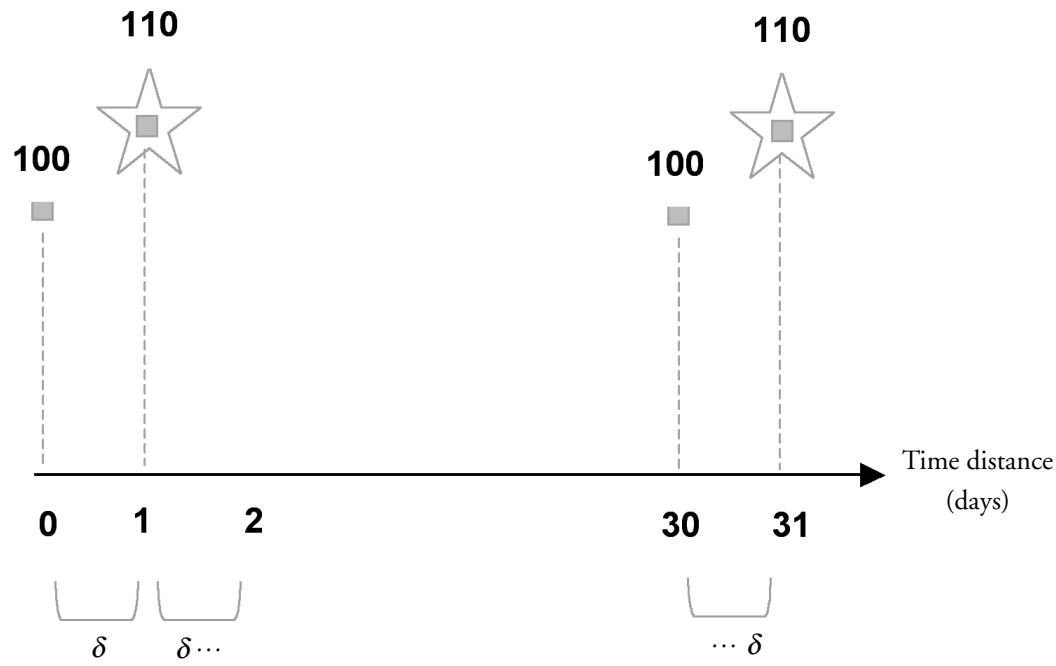

Figure 1.

This means he or she will necessarily prefer (€110, 1 day) to (€100, 0 days), and hence behave dynamically consistent. (Figure 1)

Thus, since Strotz' enormously influential paper, exponential discounting has established as the necessary mathematical structure that guarantees dynamic consistency; hence, since dynamic consistency is per se considered a rationality requirement, Samuelson's discounted utility model has been regarded also as the rational intertemporal choice model.

This strong normative support had two effects in the further development of discounted utility. First, it gave fresh impetus to the descriptive validity of the theory: given that it was deemed implausible that regular people could survive without being able to stick to their own plans, exponential discounting was hard to deny also from a positive perspective ${ }^{18}$. And second, it had a blinding effect: the rest of the assumptions underlying discounted utility were less criticized ${ }^{19}$. As a result, discounted utility established not only as the standard normative model, but also as the best attempt for a positive theory.

18. Of course, many of these arguments do not pass severe scrutiny. Here I just want to describe how such arguments have helped the establishment of discounted utility; in a later section I will try to show why they are wrong, and what implications this has had for the development of intertemporal choice theory.

19. But not unexplored: several papers have studied in depth the complete axiom system of discounted utility, discussing all assumptions and their implications. See, for instance, Koopmans (1960), Lancaster (1963), Fishburn \& Rubinstein (1982), Albrecht \& Weber (1995) and Ok \& Masatlioglu (2003). 


\section{Anomalies in Discounted Utility: The Experimental Challenge}

Over the last 25 years this view has changed. After the widening of experiments in intertemporal choice, virtually all assumptions in discounted utility have proven invalid as general principles of behavior. And interestingly, the first anomaly found to contradict discounted utility was that, instead of remaining constant over time, observed discount rates appear to decline with time (or, equivalently, discount factor $\delta_{t}$ sare increasing in time). A common interpretation of this phenomenon is that people consider postponing consumption one period a bigger sacrifice when the period is close than when it is far in the future. Discount rates that decline with time distance thus reveal 'decreasing impatience', or, as it is often referred to in the literature, hyperbolic discounting.

The finding of hyperbolic discounting has not only directly challenged discounted utility, but also opened the Pandora's Box of empirical testing that has produced a large series of other anomalies now present in the literature of intertemporal choice. Let us now revise all these anomalies in some detail.

\section{Hyperbolic Discounting}

Thaler (1981) was the first study to test the declining discount rate hypothesis. He asked subjects to specify the amounts in one month, one year and ten years they considered equivalent to receiving $\$ 15$ now. The median responses were, respectively, $\$ 20, \$ 50$ and $\$ 100$. If we compute the annual equivalent discount rate underlying these choices, we find that subjects revealed a discount rate of $345 \%$ for the one-month period, $120 \%$ for the one-year period and 19\% for the ten years horizon, a pattern that clearly supports the hyperbolic discounting hypothesis. Other studies have found similar results (Benzion, Rapoport and Yagil 1989; Chapman 1996; Chapman \& Elstein 1995; Pender 1996; Redelmeier and Heller 1993) ${ }^{20}$.

A second type of empirical support for hyperbolic discounting comes from experiments on dynamic inconsistency. Several studies report systematic preference reversals between two rewards as the time-distance to these rewards diminishes (Green, Fristoe \& Myerson 1994; Kirby \& Herrnstein 1995; Millar \& Navarick 1984; Solnick et al. 1980) ${ }^{21}$. For example, many people do in fact prefer $€ 102$ in thirty-one days over $€ 100$ in thirty days but at the same time $€ 100$ now to $€ 102$ tomorrow (see figure 2). Kirby \& Herrnstein (1995) looks at such reversals and finds an astonishing 34 out of 36 subjects who behave inconsistently. Such overwhelming results are to be explained by the fact that

20. Recently, however, Read, Airoldi \& Loewe (2005) have found that this effect disappears if subjects are told what interest rates underlies each choice, casting doubts on the universal validity of the standard decreasing-discount-rates finding.

21. These results have been also replicated in pigeons (Ainslie \& Herrnstein 1981; Green et al. 1981). 


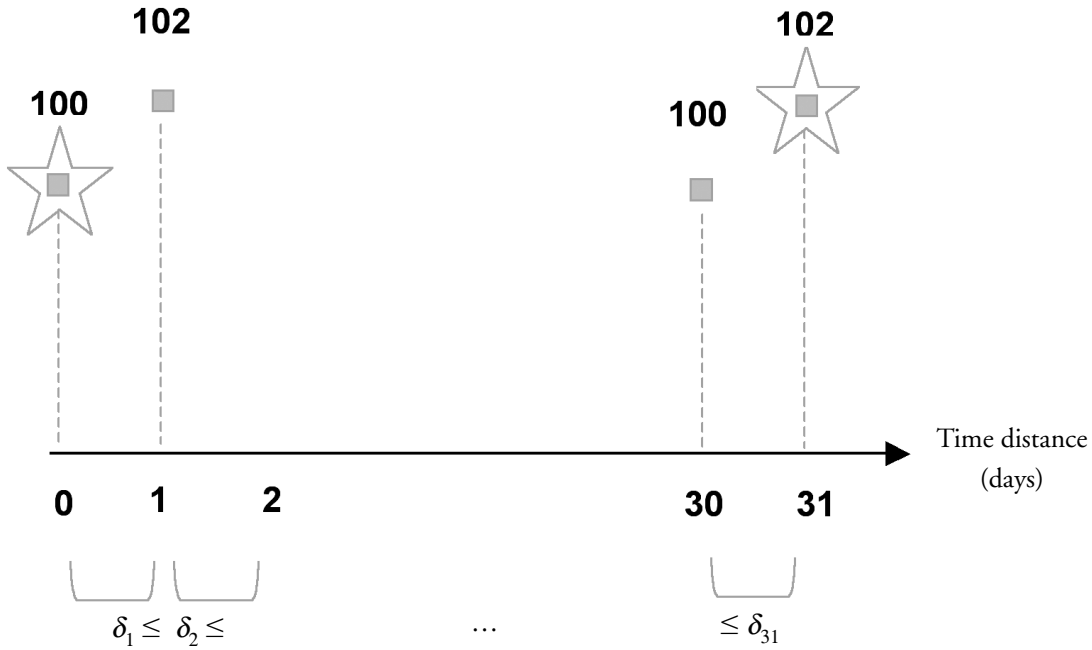

Figure 2.

their questionnaires adapted to individual preferences: the authors first asked subjects what is the shortest delay for $€ 102$ at which they would still prefer $€ 100$ today. Now imagine someone said two-days, meaning for shorter delays he would prefer the larger-later amount; then they would move both amounts forward (keeping constant the two-days distance among them) and ask subjects to choose again until either their preference reversed in favour of $€ 102$, or a certain number of questions passed. This methodology has the advantage of yielding the maximal amount of preference reversals, but, on the other hand, it may be questioned methodologically by the fact that subjects may perceive they are expected to reverse their preference. The authors did nevertheless postexperimental interviews, and report that subjects were in fact expressing their true preferences. And, in general, the finding of dynamic inconsistency is today considered robust in the literature.

Several models have been proposed to account for hyperbolic discounting but the simplest one was proposed by the psychologist Mazur (Mazur 1987)22.

$$
\begin{array}{ll}
D(t)=\left(\frac{1}{1+i \cdot t}\right) & \text { discount function } \\
\delta_{t}=\left(\frac{1+i \cdot(t-1)}{1+i \cdot t}\right) & \text { discount factor of period } t
\end{array}
$$

22. Mazur's discount function is similar to «simple interest» in mathematical finance. 
Note that the discount factor is not constant, but an increasing function of time. When objects of choice are distant in the future, deferring consumption one period is not too relevant (example: $t=50$ would mean $\delta_{50}=0,98$ for a per-period $i=0,2$, meaning a difference in value of $2 \%$ among objects in periods 49 and 50). While deferring consumption one period from the present is much more significant $\left(t=1\right.$ would mean $\delta_{1}=0,83$ for the same perperiod $i=0,2$, meaning a difference in value of $17 \%$ among outcomes in periods 0 and 1). This preference pattern may therefore produce dynamic inconsistent choices. Other more general hyperbolic discounting functions have been proposed in the literature (see Laibson 1997; Loewenstein \& Prelec 1992; Elster 1979), but a model as simple as Mazur's already captures the essence of hyperbolic discounting for our purposes here.

Hyperbolic discounting functions have helped recently explain many phenomena: they have been used to study paradoxes in the consumption-saving behaviour (Laibson 1997; Laibson, Repetto \& Tobacman 1998; Angeletos et al. 2001), or even procrastination, since hyperbolic discounting leads a person to put off an onerous activity more than he would like to from a prior perspective (O’Donoghue \& Rabin 1999c, 2001; Fischer 1999). Hyperbolic discounting also has been used to analyse addiction (O'Donoghue \& Rabin 1999a, 2000; Gruber \& Koszegi 2000; Carrillo 1999), since it predicts over consumption of highly addictive products. In sum, the hyperbolic discounting literature has been very influential and celebrated as a first big success of the interaction between psychology and economics.

More recently, however, much of this enthusiasm with hyperbolic discounting has come up against important criticism. On the one hand, Read (2001) showed that total discounting over a temporal interval increases as the interval is more finely partitioned. Such «subadditive discounting», as Read labelled it, is incompatible with any hyperbolic discount function (Read 2001). On the other hand, Rubinstein (2003) showed that hyperbolic discounting could be empirically challenged in a similar way as exponential discounting had been challenged before. In one of his experiments, for example, Rubinstein shows how many people prefer $\$ 997$ in eleven months to $\$ 1000$ in twelve months, but at the same time they prefer a sequence of four $\$ 1000$ payments to be received in $6,8,10$ and 12 months respectively, over a sequence of four $\$ 997$ payments to be received in 5, 7,9 and 11 months respectively. Note that such a time preference could never be hyperbolic, since if someone declares he prefers $\$ 997$ in eleven months to $\$ 1000$ in twelve, then for any such pair of outcomes laying closer in time, a lower discount factor would apply and would increase the preference for $\$ 997$, implying a higher preference for the $\$ 997$ sequence over the $\$ 1000$ sequence $^{23}$.

23. Rubinstein claims his results are due to the similarity of $€ 997$ and $€ 1000$ (see Rubinstein 2003 for the argument). But Loewe $\&$ Read (2005) have replicated his results controlling for the similarity explanation, and showed it is in fact the 'magnitude effect' that is responsible for this phenomenon as we will next see. 
Despite this criticism, hyperbolic discounting has established as a serious 'opponent' to exponential discounting, one representing the benefits of experimental economics and psychology. In fact, the question we may ask ourselves is why it has not achieved to displace exponential discounting, as one would reasonably expect (it explains dynamic inconsistency, it fits data statistically better — see Fredrick, Loewenstein \& O'Donoghue (2002) —, it is parsimonious, and it fits intuition). I will answer this question in the next section, but first let me describe other anomalies found in the literature over these years.

\section{Other Anomalies}

As we have shown earlier, discounted utility not only relies upon the hypothesis of constant discount rates. Many other discounted utility assumptions exist and have been tested, revealing a collection of other well known anomalies that have established in the literature in a similar way as there is a collection of expected utility anomalies (Loewenstein \& Prelec 1992; Fredrick, Loewenstein \& O’Donoghue 2002). As we will next see, Samuelson's proposed mathematical structure is unable to capture many common preference patterns.

The "sign effect»: in many studies gains are discounted at a higher rate than losses. Imagine someone receives a traffic ticket and is asked how much he is willing to pay to delay the payment by three months. Now consider the same problem framed with gains: someone has won a prize and is asked how much he would need to be paid to accept receiving the money three months later. Thaler (1981) showed the underlying discount rates differ significantly for both framings. In fact, in many studies subjects have shown a preference to incur in a loss immediately rather than delaying it (Benzion, Rapoport \& Yagil 1989; Loewenstein 1987; MacKeigan et al. 1993; Mischel, Grusec \& Masters 1969; Redelmeier \& Heller 1993; Yates \& Watts 1975).

The «magnitude effect»: larger outcomes are discounted at a lower rate than smaller outcomes. In virtually all studies that vary outcome size, a clear «magnitude effect» has been revealed by the choices of subjects, an effect that is now one of the most robust findings in intertemporal choice (Ainslie \& Haendel 1983; Benzion, Rapoport \& Yagil 1989; Chapman \& Winquist 1998; Green, Fristoe \& Myerson 1994; Green, Fry \& Myerson 1994; Holcomb \& Nelson 1992; Kirby 1997; Kirby \& Marakovic 1996; Kirby, Petry \& Bickel 1999; Loewenstein 1987; Raineri \& Rachlin 1993; Shelley 1993; Thaler 1981). See, for example, 1 month discount rates revealed in Thaler $(1981)^{24}$ :

\begin{tabular}{ll} 
Amount & 1-month equivalent \\
\hline$\$ 15$ & $\$ 20(345 \%)$ \\
$\$ 250$ & $\$ 300(219 \%)$ \\
$\$ 3000$ & $\$ 3100(39 \%)$ \\
\hline
\end{tabular}

24. 1-month equivalents are observed median values. 
The «magnitude effect» strongly affects intertemporal choices, and has been shown to explain several phenomena. One of them is, for example, the finding that a whole sequence of outcomes is discounted at a lower rate than single outcomes are (Kirby \& Guastello 2001, Ainslie \& Monterosso 2003; and also, Rubinstein 2003), an effect usually attributed to hyperbolic discounting (Ainslie \& Haslam 1992). Imagine the following four options:

\begin{tabular}{l|l|l|l|l|l|l|l|l|l} 
& oct & nov 15 & dec 15 & jan 15 & feb 15 & mar 15 & apr 15 & may 15 & jun 15 \\
\hline $\begin{array}{l}\text { Option A } \\
\text { Option B }\end{array}$ & & & & $€ 200$ & & & & & \\
\hline $\begin{array}{l}\text { Option C } \\
\text { Option D }\end{array}$ & & $€ 200$ & $€ 200$ & $€ 200$ & $€ 200$ & $\ldots 210$ & \\
\hline
\end{tabular}

Many people prefer A over B but D over C, which implies a lower discount rate for sequences. But Loewe \& Read (2005) have shown that this effect disappears if you control for the magnitude effect by asking also the following question:

\begin{tabular}{l|l|l|l|l|l|l|l|l|l} 
& oct & nov 15 & dec 15 & jan 15 & feb 15 & mar 15 & apr 15 & may 15 & jun 15 \\
\hline $\begin{array}{l}\text { Option E } \\
\text { Option F }\end{array}$ & & & & $€ 800$ & & & & \\
\hline
\end{tabular}

Virtually all the people preferring $\mathrm{D}$ over $\mathrm{C}$ chose also $\mathrm{F}$ over $\mathrm{E}$, which indicates when single outcomes have the same total value than sequences there is no apparent difference in discount rates between single outcomes and sequences of outcomes. Thus, the magnitude effect is in fact the best explanation for an apparent lower discount rate for sequences.

The "delay-speedup" asymmetry: Loewenstein (1998) found that respondents who expected receiving a VCR in one year would pay an average of \$54 to receive it immediately, while those who expected receiving it immediately demanded an average of $\$ 126$ to delay its receipt by a year. Other studies have confirmed these findings (Benzion, Rapoport \& Yagil 1989; Shelley 1993), which suggest that an individual's reference point is relevant for his intertemporal choices.

"Sequence» effects: discounted utility evaluates a sequence of outcomes by adding each outcome's discounted values, independently of whether the sequence has any particular shape (increasing or decreasing, for example). The literature has nevertheless found that people systematically prefer increasing sequences of consumption over decreasing ones adding up to the same total amount (Ariely \& Carmon 2003; Fredrick \& Loewenstein 2002; Loewenstein \& Prelec 1993; Loewenstein \& Sicherman 1991). For example, Loewenstein \& 
Sicherman (1991) found that people prefer an increasing wage profile over a declining or flat one, even after being reminded that a decreasing sequence has a higher total present value due to higher interests over the larger-sooner outcomes. Analogously, when sequences were framed as streams of pain (headache pain, for example), respondents showed a clear preference for decreasing over increasing sequences, indicating pain was preferred sooner rather than later (Chapman 2000). In general, when subjects choose among different sequences of two events people tend to save the better thing for last, contradicting the standard assumption of a positive interest rate.

In addition to this preference-for-improvement finding, other sequence effects are reported in the literature. Loewenstein \& Prelec (1993) found a preference for uniformly spreading of outcomes in a sequence. People tend to prefer $(0,1,0,1,0,1,0)$ rather than $(0,0,1,1,1,0,0$,$) showing a tendency to like even-$ ly distributed sequences. Also, research in retrospective evaluation of experiences started by Kahneman et al. (1993) has shown a preference for two particular "moments» in a sequence, the peak and the end. Several studies have found that a weighted average of experiences at these two particular points in time suffices to explain individuals' retrospective overall evaluation of experiences. The reason for it is that memory stores only highlights of an experience, and this is the only information that is afterwards used when the time comes to make a retrospective evaluation (see also Ariely \& Carmon 2003 for a review on the evidence). In sum, preferences for sequences appear to be essentially different from preferences for single outcomes. Once people perceive they are choosing among objects embedded in a sequence, they act according to a collection of new reasons regarding the specific shape of the sequence (see Read \& Powell 2000 for a qualitative study on these reasons). Put in other words: we can conclude that 'gestalt properties' matter; and discounted utility does not account for them.

We have seen a collection of anomalies that casts serious doubts on discounted utility as a descriptive theory of intertemporal choice. The reported findings are quite intuitive, too; in fact, most of us could well be represented by these preference patterns, despite which they cannot be accommodated into Samuelson's mathematical structure. Now the obvious questions are the following: why is discounted utility still regarded as the standard approach? Why not use hyperbolic discounting instead, which appears to perform empirically better, and is as parsimonious as exponential discounting? Or, why has no other alternative model really established? These questions are particularly intriguing: intertemporal choice is a perfect example of how a specific social theory can become an interdisciplinary field of research, and open itself to experimental scrutiny ${ }^{25}$; what is then obstructing its further development?

25. Contrary to other economic theories, intertemporal choice has even achieved both predictive improvement and interest in securing such improvement, the two features Rosenberg regards as symptoms of epistemological health (Rosenberg 1992). 


\section{Intertemporal Choice after the Experimental Challenge: Rationality as Dynamic Consistency Reconsidered}

In order to answer the questions we just posed, we need to go back first to what the concept of rationality means for economic science. As it is widely known, choice theory is based upon the idea of preference relations describing people's behaviour. Preference relations' particular structure - completeness and transitivity - ensures we can represent such preferences by a function assigning a value to each object of choice, which makes it possible to interpret an individual's choices as if he aimed at maximizing the value of this function ${ }^{26}$. Now rational choice theory consists basically in assuming people do in fact have such (stable ${ }^{27}$ ) preference relations. But why should they?

Many economists like to answer with the money-pump argument. According to this idea, an individual with intransitive preferences would be easy to exploit by an arbitrageur. Suppose an individual's preferences over three objects were as follows:

$$
A>B \text { and } B>C \text {; but } C>A
$$

This individual will thus be ready to exchange $\mathrm{C}$ plus a certain quantity (say, one cent) to obtain $\mathrm{B}$, which he values more. But then, he will also accept exchanging $\mathrm{B}$ plus one cent to get A; and finally, also A plus one cent to get C. Such a cycle would bring him back to his original situation possessing $\mathrm{C}$, but having spent 3 cents! Thus, this subject can easily be exploited by an arbitrageur, who could keep indefinitely pumping money out of him until complete ruin.

The money-pump argument is far from being uncontroversial from a technical-economical point of view (see, among others, Cubitt \& Sudgen 2001; Machina 1989; McClennen 1990; Sudgen 1991; Anand 1993; Kelsey \& Milne 1997; Yaari 1998). But its fundamental idea is that economic theory has reasons to believe that most of the people behave most of the time transitively, or otherwise they would not 'survive'. A basic normative principle - it is bad to be ruined- becomes a positive theory by arguing that exposure to a moneypump would immediately be exploited by arbitrageurs.

26. This idea has produced much confusion among economists and non-economists. If we restrict our attention to the descriptive meaning of this theory, it does not mean to assume that people consciously optimize behaviour; it just says if choices are consistent in the sense of complete and transitive, then they can be interpreted as the result of an optimization of an arbitrary function. (Note, in fact, that the argument would work also if we substitute optimization by minimization: a preference relation can be represented by a function so that most valued options are assigned the lowest values, and we can thereafter conclude the individual aims at minimizing utility). The key point is that preferences are consistent in a way as to be interpreted as the result of the choice of the first option in a ranking.

27. Stability of preference relations is very important, since the opposite - changing preferences - would be completely non-informative; any possible behaviour would fit in the preference relations' theory (Rosenberg 1992). 
Let us now go back to intertemporal choice. In a previous section we saw that dynamic consistency is considered a rationality principle for intertemporal choice. The rationality of dynamic consistency can be founded ultimately on the same argument we just saw. A dynamic inconsistent individual could be brought to ruin by an arbitrageur. To illustrate this, imagine that Alex has a lasting preference for $€ 11$ in 24 hours over $€ 10$ in 22 hours, but prefers $€ 10$ immediately to $€ 11$ in two hours. Helene offers to sell him $€ 11$ in 24 hours for $€ 10$ in 22 hours. Alex agrees. 22 hours later, Alex gives Helene $€ 10$. But now his preferences have changed and he would prefer keeping the $€ 10$ rather than getting $€ 12$ in two hours. Helene thus offers to give him the $€ 10$, if he agrees to pay her $€ 11$ plus, say, one cent in two hours. Alex agrees and in two hours Helene is one cent better off. Helene then offers to sell Alex $€ 11$ in 24 hours... and so on. Now a hyperbolic discounter, the argument continues, has precisely such a preference structure, and thus could easily be exploited to ruin. On the contrary, exponential discounters are invulnerable to such money-pumps, and are therefore expected to proliferate in society.

The problem of such quasi-evolutionary foundations of social theories is that they are only 'quasi' right. In effect, imagine most of the people were sophisticated hyperbolic discounters as follows: if they detect an arbitrageur, they do not make any deal with him (they give up a certain opportunity to be better off in order to morally punish arbitrageurs) ${ }^{28}$; in any other situation, they behave normally. This means there would be no incentives at all for arbitrageurs to operate. We could then perfectly observe a vast majority of hyperbolic discounters behaving dynamically inconsistent in their every day life, without causing their selves any fatal damage by doing so. The money-pump-based justification of dynamic consistency as a rationality principle thus relies upon viewing people as naive decision-makers.

Moreover; suppose now there were no sophisticated behaviours, and that hyperbolic discounters were naively exposed to exploitation. We still need certain preconditions in order to support the money-pump defence of exponential discounting: for example, it is needed that the specific arbitrage opportunities are enough to make a living out of it. How much work would be needed by the arbitrageurs to earn how much money? Would this be more worth doing than a regular job? Would the moral discomfort outweigh the monetary incentives? If these circumstances are not met, we simply cannot infer dynamically inconsistent individuals would not survive. Hence, the money-pump argument also relies upon the worthiness of arbitrage for arbitrageurs.

Finally, I want to point at a third objection to the money-pump argument for dynamic consistency, due to Albrecht \& Weber (1995). Many decisions are completely binding, not subject to future reconsideration. For those kinds of decisions there is no possible argument in favour of exponential discount-

28. The existence of punishing behaviour that goes against one's interests is now empirically well founded in the literature (see, for example, Thaler (1989) on the so-called ultimatum game). 
ing based on dynamic consistency. When decisions are irrevocable, nothing prevents the individual to discount future values hyperbolically since such behaviour would not produce any dynamic inconsistency to be exploited by arbitrageurs. Thus, even if the money-pump argument should have any validity, this very same validity would depend on the decision context.

As we can see, then, dynamic consistency and money-pump arguments are not rigorous principles to sustain exponential discounting as a descriptive theory of intertemporal choice. But, are they valid normative principles? Is it true that being dynamically consistent is necessarily 'good'? The answer is also 'no'. There is no ultimate reason why someone should obey his previous decisions, for we cannot grant a past 'self' a higher moral authority than a present 'self'. As Strotz put it, we may ask ourselves «at which date should sovereignty inhere in the [decision] maker» (Strotz 1956, p179). The concept of consumer sovereignty has no meaning in the context of dynamic decision-making (Strotz 1956) and, for that reason, Samuelson himself regarded discounted utility as lacking normative legitimacy as a rational intertemporal choice model (Samuelson 1937).

Now despite all these considerations, economic thought has put the straitjacket of dynamic consistency to intertemporal choice theories. First it has used the principle stating dynamic inconsistency is bad per se to automatically assimilate dynamic consistency to rationality. Then it has shown that only exponential discounting is completely free of inconsistencies, and thus the only possible rational intertemporal choice theory. Finally, it has used this normative support to argue that exponential discounting ought to be also the standard descriptive intertemporal choice model. Experimental work has uncovered the flaws of such reasoning. But the strong normative case for exponential discounting has restricted much of the attention to the exponential-vshyperbolic discounting debate, and blinded the many other fundamental problems in discounted utility we have reviewed in the previous section.

The development of intertemporal choice has in consequence for many years been interrupted by principles founded in what we could consider «folk logic». These principles have hindered the ability of the theory to evolve between the 50's and the 90's, and, to some extent, it continues obstructing its further development. And the dynamic consistency requirement has proven particularly hard to withdraw from intertemporal choice, since its normative limitations hide behind a basic intuition identifying inconsistency with the bad ${ }^{29}$. But this intuition is wrong. There is no ultimate reason why someone behaving only sometimes inconsistently is producing harm to himself, for there is no ultimate reason why the 'planner' makes always good plans for the 'doer'. There may indeed be reasons to consider someone who is continuously abandoning his plans is producing himself harm; but the fact that someone's pref-

29. We could see the strong power of this moral intuition in the US presidential campaign 2004, where huge amounts of money were devoted to prove electors that one candidate was a «flip-flap», changing continuously his mind on important issues. 
erences are such that they may result in dynamic inconsistency once does not imply he will be exposed to continuous dynamic inconsistency, as if an iron rod had totally damaged his brain. The identification of dynamic inconsistent preference structures with the bad relies thus on an invariance assumption saying that preferences remain the same across all periods and circumstances, including the situation in which someone perceives he is catched in a moneypump. Naturally, any mathematical representation of choice needs to make such simplifications, or the theory would become completely impossible to handle; but the choice of the normative principles that ought to define validity of theoretical models should not drag these simplifications.

Fortunately, today intertemporal choice seems to be starting to undo this straitjacket and rapidly generating valuable alternative theories that are free from its complex about dynamic inconsistency, as we have seen in a previous section. Experimental work in intertemporal choice has been crucial in this process, since it has made the invisible straitjacket visible. But the empirical findings had been impossible without knowing before what to test. Intertemporal choice hence owes its progress to the spirit of Samuelson's «statistical experiment» (Samuelson 1937), consisting of specifying a mathematical model even without having complete confidence either on its normative or on its positive validity. This may indicate us social scientists that analytical thinking is probably not only convenient as guarantor of the internal consistency of our theories, but -more importantly-a necessary condition for their empirical scrutiny, a scrutiny that turns out to be crucial to reveal hidden assumptions. A wrong, specified theory will be proven wrong sooner or later; but a wrong, unspecified theory may remain invisibly wrong forever.

\section{Summary and Conclusions}

The aim of this paper has been to describe the evolution of a very dynamic theory: the theory of intertemporal choice. I have presented the first economic thinking on intertemporal decision-making, and exposed how it resulted in Samuelson's famous discounted utility model; then I have described how and why discounted utility became the standard approach to intertemporal choice in economics through the alleged normative and positive validity of dynamic consistency. Next, I have reviewed how the widening of experiments challenged discounted utility together with the dynamic consistency hypothesis, and turned intertemporal choice into a truly interdisciplinary field of research. Finally, I have discussed the foundations of dynamic consistency and proved that it is neither normatively nor descriptively justified as a necessary axiom of rational intertemporal choice. I have also showed how until only recently, the dynamic consistency debate has had a blinding effect on the relative importance attributed to other fundamental anomalies in discounted utility. And this blinding effect can be regarded as a further side-effect of the excessive role given to dynamic consistency along these years. I have thus concluded that dynamic consistency has been acting as an invisible straitjacket obstructing 
the development of intertemporal choice theory, and that it is only by undoing it that this field of research can achieve in the future a satisfactory understanding of human decision-making.

\section{References}

Ainslie, G. (1975). «Specious Reward: A Behavioral Theory of Impulsiveness and Impulse Control». Psychological Bulletin, 82, 463-469.

Ainslie, G.; Haendel, V. (1983). «The Motives of Will». In GotTheil, E.; Druley, K.; SkOlda, T.; WaXman, H. (eds.). Etiologic Aspects of Alcohol and Drug Abuse. Springfield, IL: Charles C. Thomas.

Ainslie, G.; Haslam, N. (1992). «Hyperbolic Discounting». In Loewenstein, G.; Elster, J. (eds). Choice over Time, Russel Sage Foundation, p. 57-92

Ainslie, G.; Herrnstein, R. J. (1981). "Preference Reversal and Delayed Reinforcement». Animal Learning and Behavior, 9, 476-482.

Ainslie, G.; Monterosso (2003). «Building Blocks of Self-Control: Increased Tolerance for Delay with Bundled Rewards». Journal of The Experimental Analysis of Behaviour 79: 37-48.

Albrecht, M.; Weber, M. (1995). «Hyperbolic Discounting Models in Prescriptive Theory of Intertemporal Choice». Zeitschrift fir Wirtschafts- und Sozialwissenschaften, $115,535-568$.

Anand, P. (1993). Foundations of Rational Choice Under Risk. Clarendon Press.

Angeletos, G.M.; Laibson, D.; Tobacman, J.; Repetto, A.; Weinberg, S. (2001). "The Hyperbolic Consumption Model: Calibration, Simulation, and Empirical Evaluation». Journal of Economic Perspectives, 15(3), p. 47-68.

Ariely, D.; Carmon, Z. (2003). «Preferences Over Sequences of Outcomes». In: LoeWensteIn, George; Read, Daniel; Baumeister, Roy (eds.). Time and Decision: Economic and Psychological Perspectives on Intertemporal Choice. New York: Russell Sage Foundation Press.

BENZION, U.; RAPOPORT, A.; YAGIL, J. (1989). «Discount Rates Inferred from Decisions —an Experimental-Study». Management Science, 35(3), 270-284.

BÖHM-BAWERK, Eugen von (1890) [1884]. Capital and Interest: A Critical History of Economical Theory. London: Macmillan Company.

CARrillo, J.D. (1999). «Self-Control, Moderate Consumption and Craving». CEPR discussion paper 2017.

Chapman, G.B. (1996). "Temporal Discounting and Utility for Health and Money». Journal of Experimental Psychology-Learning Memory and Cognition, 22(3), 771-791.

- (2000). «Preferences for Improving and Declining Sequences of Health Outcomes». Journal of Behavioral Decision Making, 13, p. 203-18.

ChapMAn, G.B.; Elstein, A.S. (1995). «Valuing the Future - Temporal Discounting of Health and Money». Medical Decision Making, 15(4), 373-386.

ChaPMAN, G.B.; WINQUIST, J.R. (1998). «The Magnitude Effect: Temporal Discount Rates and Restaurant Tips». Psychonomic Bulletin \& Review, 5(1), 119-123.

CubitT, R.; Sudgen, R. (2001). «On Money Pumps». Games and Economic Behavior 37, 121-160.

Damasio, A. (1994). Descartes' Error. New York: G.P. Putnam's Sons.

Elster, J. (1979). Ulysses and the Sirens. Cambridge: Cambridge University Press. 
Fischer, C. (1999). «Read This Paper Even Later: Procrastination with TimeInconsistent Preferences». Discussion Paper 99-20, Resources for the Future.

FishbuRn, P.; RUBinsteIn, A. (1982). «Time Preference». International Economic Review, 23, 677-694.

FISHER, Irving (1930). The Theory of Interest. New York: Macmillan Company.

Frederick, S.; Loewenstein, G.; O’Donoghue, T. (2002). «Time Discounting and Time Preference: A critical review». Journal of Economic Literature, 40(2), 351-401.

Frederick, S.; Loewenstein, G. (2002). «The Psychology of Sequence Preferences». Working paper. Cambridge: Massachusetts Institute of Technology, Sloan School of Management.

Green, L.; Fisher, E.B., Jr.; Perlow, S.; Sherman, L. (1981). «Preference Reversal and Self-Control: Choice as a function of reward amount and delay». Behaviour Analysis Letters, 43-51

Green, L.; Fristoe, N.; Myerson, J. (1994). «Temporal Discounting and Preference Reversals in Choice Between Delayed Outcomes». Psychonomic Bulletin \& Review, 1(3), 383-389.

GreEN, L.; FrY, A.F.; Myerson, J. (1994). «Discounting of Delayed Rewards: A LifeSpan Comparison». Psychological Science, 5, 33-36.

Green, L.; Myerson, J.; McFadden, E. (1997). «Rate of Temporal Discounting Decreases with Amount of Reward». Memory \& Cognition, 25(5), 715-723.

GrUbeR, J.; Koszegi, B. (2000). «Is Addiction Rational? Theory and Evidence». NBER Working Paper 7507.

Holcomb, J.H.; Nelson, P.S. (1992). «Another Experimental Look at Individual Time Preference». Rationality and Society, 4, 199-220.

Jevons, W.S. (1888) [1871]. The Theory of Political Economy. London: McMillan. KAHNEMAN, D.; WAKKeR, P.; SARIN, R. (1997). «Back to Bentham? Explorations of Experienced Utility». Quarterly Journal of Economics, 112, p. 375-405.

KelseY, D.; Milne, F. (1997). «Induced Preferences, Dynamic Consistency and Dutch Books». Economica, 64, 471-81.

KIRBY, K.N. (1997). «Bidding on the Future: Evidence Against Normative Discounting of Delayed Rewards». Journal of Experimental Psychology-General, 126(1), 54-70.

Kirby, K.N.; Guastello, B. (2001). "Making Choices in Anticipation of Similar Future Choices Can Increase Self-Control». Journal of Experimental Psychology: Applied, 7(2), 154-164.

KirbY, K.N.; HerRnstein, R.J. (1995). «Preference Reversals Due to Myopic Discounting of Delayed Reward». Psychological Science, 6(2), 83-89.

KirbY, K.N.; MARAKOVIC, N.N. (1996). «Delay-Discounting Probabilistic Rewards: Rates Decrease as Amounts Increase». Psychonomic Bulletin \& Review, 3(1), 100-104.

Kirby, K.N.; Petry, N.M.; BicKeL, W.K. (1999). «Heroin Addicts Have Higher Discount Rates for Delayed Rewards than Non-Drug Using Controls». Journal of Experimental Psychology: General, 128, 78-87.

KoOPMANS, T.C. (1960). «Stationary Ordinal Utility and Impatience». Econometrica, 28, 287-309.

LAIBSON, D. (1997). «Golden Eggs and Hyperbolic Discounting». Quarterly Journal of Economics, 112, 443-477.

Laibson, D.; Repetto, A.; Tobacman, J. (1998). "Self-Control and Saving for Retirement». Brookings Papers on Economic Activity, 191-196.

LanCASTeR, K. (1963). «An Axiomatic Theory of Consumer Time Preference». International Economic Review 4, 2210-231. 
Loewe, G.; Read, D. (2005). «Constant Sequences vs. Single Amounts: The SumAt-Start Effect». (In progress).

Loewenstein, G. (1987). «Anticipation and the Valuation of Delayed Consumption». Economic Journal, 97, 666-684.

- (1988). «Frames of Mind in Intertemporal Choice». Management Science, 34, p. 200-14.

Loewenstein, G.; O’Donoghue, T.; Rabin, M. (2003). «Projection Bias in Predicting Future Utility». The Quarterly Journal of Economics, MIT Press, vol. 118(4), p. 12091248.

Loewenstein, G.; Prelec, D. (1992). «Anomalies in Intertemporal Choice - Evidence and an Interpretation». Quarterly Journal of Economics, 107(2), 573-597.

- (1993). "Preferences for Sequences of Outcomes». Psychological Review, 100(1), 91-108.

Loewenstein, G.; Read, D.; Baumeister, R. (ed.) (2003). Time and Decision: Economic and Psychological Perspectives on Intertemporal Choice. New York: Russell Sage Foundation.

Loewenstein, G.; Sicherman, N. (1991). «Do Workers Prefer Increasing Wage Profiles?». Journal of Labor Economics, 9(1), 67-84.

Machina, M. (1989). "Dynamic Consistency and Non-Expected Utility Models of Choice Under Uncertainty». Journal of Economic Literature 27, 1622-1668.

MacKeigan, L.D.; Larson, L.N.; Draugalis, J.R.; BoOtMan, J.L.; BrunS, L.R. (1993). «Time Preference for Health Gains Versus Health Losses». PharmacoEconomics, 3, 374-386.

Macmillan, M. (2000). An Odd Kind of Fame. Cambridge: MIT Press.

MANUCK, S.B.; FlorY, J.D.; MuldoOn, M.F.; FERRELl, R. (2003). «A Neurobiology of Intertemporal Choice». In: LoEWENSTEIN, G.; READ, D.; BAUMEISTER, R. (ed.). Time and Decision: Economic and psychological perspectives on intertemporal choice. New York: Russell Sage Foundation, p. 139-172.

MAZUR, J.E. (1984). «Tests of an Equivalence Rule for Fixed and Variable Delays». Journal of Experimental Psychology: Animal Behavior Processes, 10, 426-436.

McClennen, E. (1990). Rationality and Dynamic Choice. Cambridge, England: Cambridge University Press.

Millar, A.; NAVARICK, D.J. (1984). "Self-Control and Choice in Humans: Effects of Video Game Playing as a Positive Reinforcer». Learning and Motivation 15, 203-218.

Mischel, W.; GruseC, J.; Masters, J.C. (1969). «Effects of Expected Delay Time on the Subjective Value of Rewards and Punishments». Journal of Personality and Social Psychology, 11, 363-373.

O'Donoghue, T.; Rabin, M. (1999a). «Addiction and Self Control». In ElSTER, Jon (ed.). Addiction: Entries and Exits. New York: Russel Sage Foundation.

- (1999c). «Incentives for Procrastinators». Quarterly Journal of Economics, 114(3), 769-816.

- (2000). «Addiction and Present-Biased Preferences». Center for Analytic Economics Working Paper 02-10, Cornell University.

- (2001). Choice and Procrastination. Quarterly Journal of Economics, 116(1), 121-160.

OK, E.A.; Masatlioglu, Y. (2003). A General Theory of Time Preferences. Levine's Bibliography 234936000000000089. UCLA: Department of Economics.

PendeR, J.L. (1996). «Discount Rates and Credit Markets: Theory and Evidence From Rural India». Journal of Development Economics, 50, 257-296. 
RAE, J. (1905) [1834]. The Sociological Theory of Capital. London: McMillan.

RAINERI, A.; RACHLIN, H. (1993). «The Effect of Temporal Constraints on the Value of Money and Other Commodities». Journal of Behavioral Decision Making, 6, 77-94.

READ, D. (2001). «Is Time-Discounting Hyperbolic or Subadditive?». Journal of Risk and Uncertainty, 23(1), 5-32.

- (2004). «Intertemporal Choice». In KoeHLER, D.; HarveY, N. (eds.). The Blackwell handbook of judgment and decision making. Oxford: Blackwell.

ReAD, D.; AIROLDI, M.; LOEWE, G. (2005). «Intertemporal Tradeoffs Priced in Interest Rates and Amounts: a Study of Method Variance». (In progress)

READ, D.; Powell, M. (2002). «Reasons for Sequence Preferences». Journal of Behavioral Decision Making, 15, 433-460.

Read, D.; Roelofsma, P.H. (2003). «Subadditive Versus Hyperbolic Discounting: A Comparison of Choice and Matching». Organizational Behavior and Human Decision Processes, 91, 140-153.

Redelmeier, D.A.; Heller, D.N. (1993). «Time Preferences in Medical Decision Making and Cost-Effectiveness Analysis». Medical Decision Making, 13, 212-217. Rosenberg, A. (1992). Economics: Mathematical Politics or Science of Diminishing Returns? Chicago: Chicago University Press.

Rubinstein, A. (2003). «Economics and Psychology? The Case of Hyperbolic Discounting». International Economic Review, vol. 44, p. 1207-1216.

Rubinstein, M. (2003). «Great Moments in Financial Economics: I. Present Value». Journal of Investment Management (first quarter).

Samuelson, P. (1937). "A Note on Measurement of Utility». Review of. Economic Studies, vol. 4, n. ${ }^{\circ}$ 2, p. 155-161.

Shelley, M.K. (1993). «Outcome Signs, Question Frames and Discount Rates». Management Science, 39(7), 806-815.

Solnick, J.V.; KannenberG, C.H.; Eckerman, D.A.; Waller, M.B. (1980). «An Experimental Analysis of Impulsivity and Impulse Control in Humans». Learning and Motivation, 11, 61-77.

Strotz, RH. (1956). «Myopia and Inconsistency in Dynamic Utility Maximization». Review of Economic Studies, 23, 165-180.

Sugden, R. (1991). «Rational Choice: a Survey of Contributions From Economics and Philosophy». The Economic Journal, 101: 751-85.

THALER, R. (1981). «Some Empirical Evidence of Dynamic Inconsistency». Economics Letters, 8, 201-207.

- (1989). "Anomalies: The Ultimatum Game». Journal of Economic Perspectives, 2195-206.

YAARI, M. (1998). "On the Role of "Dutch Books" in the Theory of Choice under Risk». In JaCOBS, D.; KALAI, E.; KAMIEN, M. (eds.). Frontiers of Research in Economic Theory. Cambridge: CUP, p. 33-46.

Yates, J.F.; WaTtS, R.A. (1975). «Preference for Deferred Losses». Organizational Behavior and Human Performance, 13, 294-306. 